Original Research Article

\title{
Cost variation analysis of various brands of anti-epileptic drugs currently available in Indian pharmaceutical market
}

\author{
Saiyadali A. Allisabanavar*, Narayana Reddy S.
}

Department of Pharmacology, Bangalore Medical College and Research Institute, Fort, K R Road, Bengaluru, Karnataka 560002, India

Received: 19 April 2017 Accepted: 16 May 2017

*Correspondence to: Dr. Saiyadali A. Allisabanavar, Email: saiyadali06bims@ gmail.com

Copyright: () the author(s), publisher and licensee Medip Academy. This is an openaccess article distributed under the terms of the Creative Commons Attribution NonCommercial License, which permits unrestricted noncommercial use, distribution, and reproduction in any medium, provided the original work is properly cited.

\begin{abstract}
Background: Epilepsy is a common neurological disorder affecting about 10 million persons in India. The compliance to a particular antiepileptic drug is highly dependent on the cost of the drug which directly translates into success or failure of therapy. Hence there is a need for all clinicians to keep themselves updated with the latest prices and price variation of the commonly prescribed drugs. This study aims to analyze cost variation of various brands of antiepileptic drugs currently available in Indian pharmaceutical market.

Methods: Current Index of Medical Specialities July-October 2016 edition was referred to know the maximum and minimum price in INR of various brands of anti- epileptic drugs in India. Further analysis was done by using Percentage Cost Variation.

Results: There is wide variation in the prices of different brands of same antiepileptic agents in Indian market. The highest \% cost variation was found for diazepam 5mg tablet (374.42), followed by lorazepam $2 \mathrm{mg}$ tablet (213.63), carbamazepine $100 \mathrm{mg}$ syrup/5ml-100ml (172.58), levetiracetam $1000 \mathrm{mg}$ FCtablet (168.57), lamotrigine $25 \mathrm{mg}$ DIS- tablet (150), clobazam $10 \mathrm{mg}$ tablet (147.37), clonazepam $0.5 \mathrm{mg}$ tablet (145.90), oxcarbazepine $150 \mathrm{mg}$ tablet (89.46), gabapentin 300mg capsule (71.67), valproic acid 200mg FC-tablet (58.62), divalproex sodium 500mg ER-tablet (47.82), topiramate 50mg tablet (41.66) and lowest \% cost variation was of phenytoin sodium $300 \mathrm{mg}$ tablet (0.23).

Conclusions: The average percentage price variation of different brands of same oral anti-epileptic drug in Indian market is very wide. To counter act such cost variation, physicians should be encouraged to prescribe a medication brand with low cost. This in turn reduces the unnecessary economic burden to the patients.
\end{abstract}

Keywords: Antiepileptic drugs, Cost analysis, Cost variation

\section{INTRODUCTION}

Epilepsy is the most common neurological condition worldwide affecting people of all ages. ${ }^{1}$ It is defined by International League Against Epilepsy (ILAE) as a condition characterized by recurrent (two or more) epileptic seizures, unprovoked by any immediate identified cause. ${ }^{1}$ Around 50 million people worldwide have epilepsy with nearly $80 \%$ of epileptic patients residing in developing countries. ${ }^{2}$ There are about 10 million persons with epilepsy in India with a prevalence of $1 \% .^{3}$
Epilepsy is one of the major causes of morbidity, mortality and needs long-term treatment. The treatment of epilepsy is a challenging task while selecting an appropriate drug or a combination of drugs that controls seizures most effectively at an acceptable level of adverse effects, taking into account the cost of the drug. The consideration of medication cost is an important aspect in health economics and plays a crucial role in patient's care especially in developing countries. ${ }^{4}$ It is also an essential part of rational drug prescription influencing compliance with treatment. ${ }^{5}$ 
Availability of anti-epileptic drugs under different dosage forms with different brands with large cost variation in India creates a lot of problems for the physicians in choosing the less costlier drug for individual patients. ${ }^{3}$ Due to increased cost variation in the anti-epileptic drugs, there is decreased compliance which in turn increases the seizure frequency and consequently leads to decrease in the quality of life, adding to the economic burden for patients. ${ }^{6}$ The awareness of cost variation of anti-epileptic drugs can be applied for more economical treatment regimen to improve the patient compliance and decrease the rate of failure of therapy.

The paucity of literature on cost effective analysis of antiepileptic drugs implies the need for cost analysis of available formulations of anti-epileptic drugs in the practice of medicine and hence the above study was designed.

This study aims to analyze cost variation of various brands of anti-epileptic drugs currently available in Indian pharmaceutical market.

\section{METHODS}

This was an analytical study. "Current Index of Medical Specialities July-October 2016" edition was referred to analyze the maximum and minimum price in INR (per 10 tablets) of anti-epileptic drugs in all available strengths and dosage forms being manufactured by different companies in India. ${ }^{7}$

Anti-epileptic drug formulations with same strength, dose and number were included for the study. The drugs being manufactured by only one company and fixed dose combinations were excluded.

Further analysis was done by using Percentage Cost Variation of the costliest to cheapest of the various brands of anti-epileptic drugs. From this we can know that how many times the costliest brand costs more than the cheapest brand in each group.

Percentage cost variation was calculated as follows. ${ }^{8}$

Cost variation $(\%)=\frac{\text { Maximum cost-minimum cost }}{\times 100}$ Minimum cost

\section{RESULTS}

The prices of anti-epileptic drugs manufactured by different pharmaceutical companies were analyzed. Figure 1 shows percentage cost variation of anti-epileptic drugs used as mono therapy.

The present study showed a very high variation in the maximum and minimum price of anti-epileptic drugs which is being manufactured by several different companies in India (Figure 2).

The cost ratio was also observed to be very high (Figure 3).

There is wide variation in the prices of different brands of same anti-epileptic agents in Indian market. The highest $\%$ cost variation was found for diazepam $5 \mathrm{mg}$ tablet (374.42), followed by lorazepam $2 \mathrm{gm}$ tablet (213.63), carbamazepine $100 \mathrm{mg} \quad$ syrup/5ml-100ml (172.58), levetiracetam 1000mg FC-tablet (168.57), lamotrigine 25mg DIS- tablet (150), clobazam $10 \mathrm{mg}$ tablet (147.37), clonazepam $0.5 \mathrm{mg}$ tablet (145.90) ,oxcarbazepine $150 \mathrm{mg}$ tablet (89.46), gabapentin 300mg capsule (71.67), valproic acid 200mg FC-tablet (58.62), divalproex sodium $500 \mathrm{mg}$ ER-tablet (47.82), topiramate $50 \mathrm{mg}$ tablet (41.66) and lowest \% cost variation was of phenytoin sodium $300 \mathrm{mg}$ tablet (0.23).

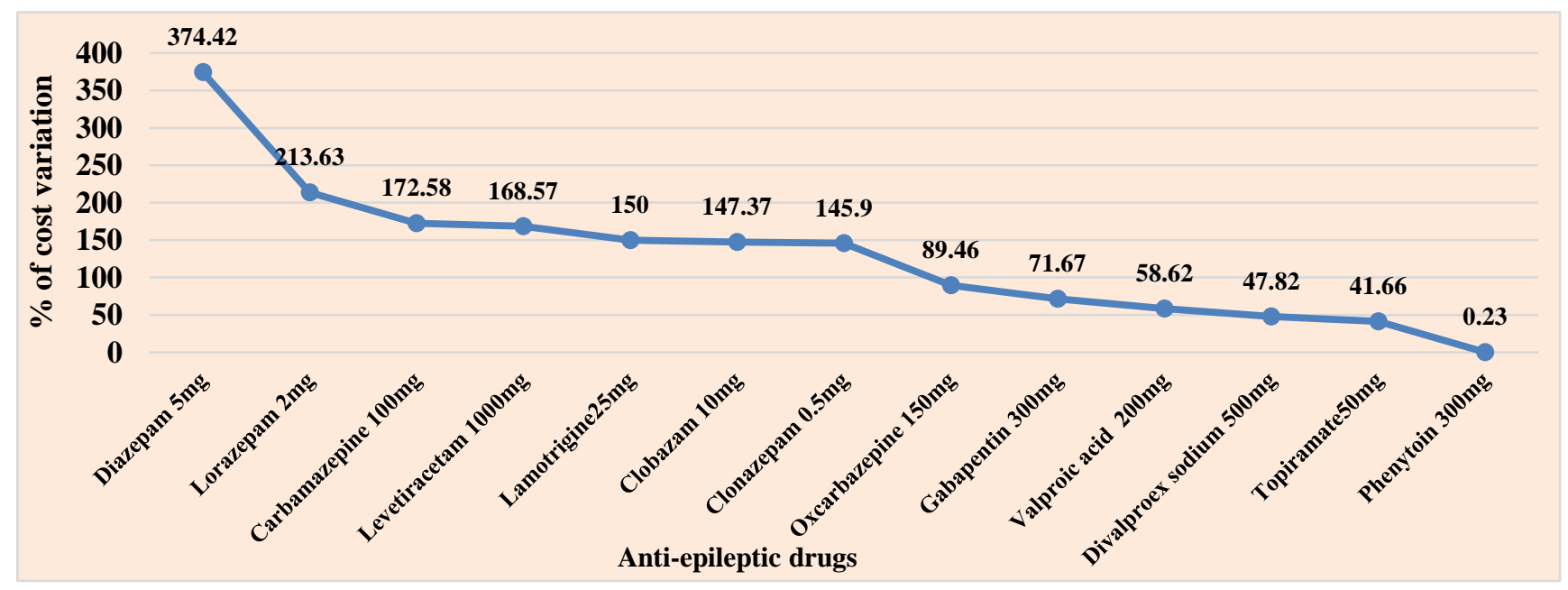

Figure 1: Percentage cost variation of anti-epileptic drugs. 


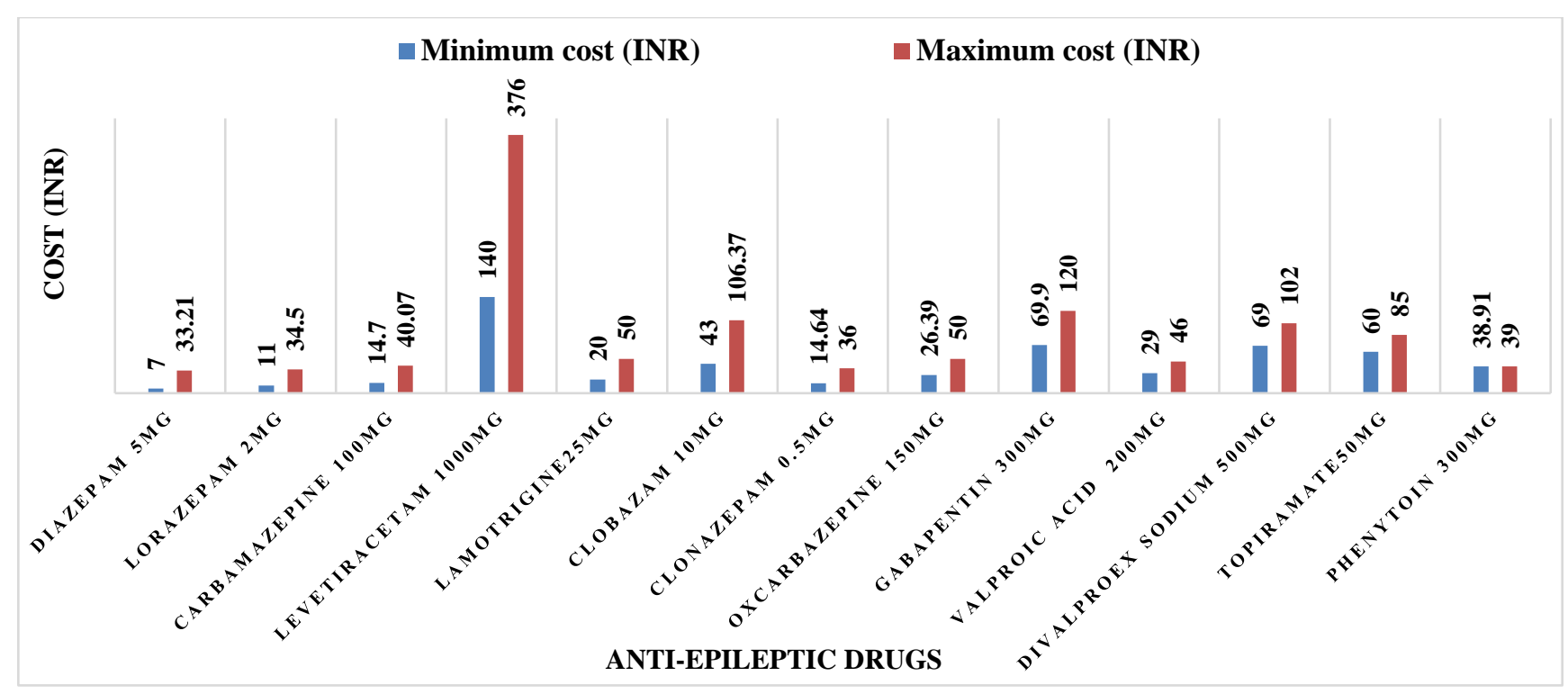

Figure 2: Cost difference [min and max] of anti-epileptic drugs.

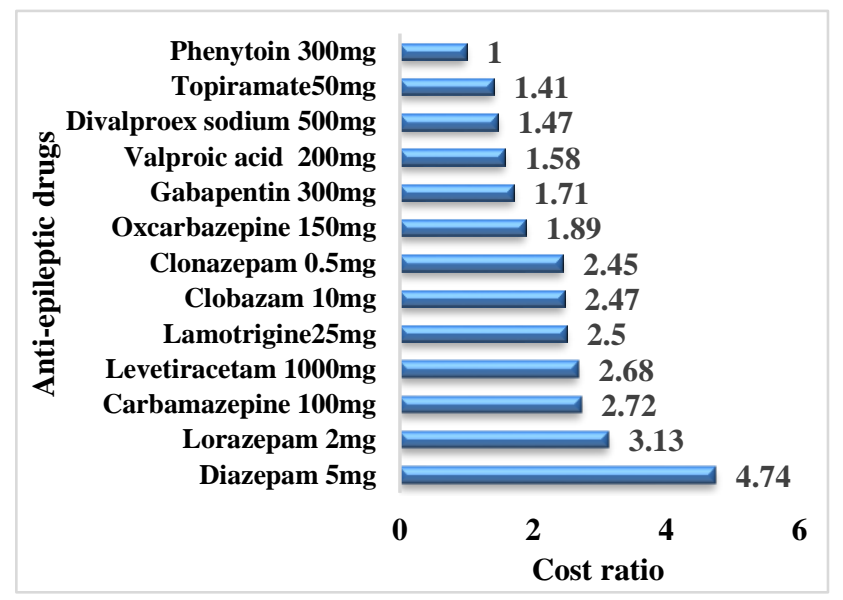

Figure 3: Cost ratio of anti-epileptic drugs.

\section{DISCUSSION}

The present study showed a very high variation in the maximum and minimum price of anti epileptic agents (Figure 1). The percentage variation in the cost was above $100 \%$ with most of the anti epileptic drugs (Figure 3 ) and there is substantial variation in the cost of different brands of same antiepileptic agents in Indian market which is consistent with the results from previous studies. ${ }^{9-11}$

Higher medication costs have been found to be a reason for medication non-adherence. ${ }^{12}$ and has been found to be related to adverse health outcomes. Medication noncompliance can be the single most common reason for treatment failure in epilepsy. It has been estimated that up to $60 \%$ of patients with epilepsy are noncompliant. Non-compliance of the drug therapy results in progression of the disease which increases the overall medical care costs dramatically. Treatment with generic anti-epileptic drugs have been found to have fewer adverse seizure-related clinical outcomes and improved treatment adherence than treatment with brand name versions. The costly brand of same generic drug is scientifically proved to be in no way superior to its economically cheaper counterpart. ${ }^{13}$

Prescribing doctors should pay due importance to the drug prices in a country like India where majority of patients are paying out of their pockets for their medical bills and are not covered by insurance schemes. It has been observed that more than $80 \%$ health financing is borne by patients in India. ${ }^{14}$ It has been observed that doctors have suboptimal awareness of drug cost. In such situation if costly brands are prescribed patients has to pay unnecessarily more money and that creates an economic burden and can affect the compliance on the patient counterpart. The situation can be improved if drug cost is given greater emphasis during medical training program of doctors. ${ }^{15}$

Currently, very few medicines are under drug prices control order. Government should bring more number of antiepileptic drugs under price control. Due consideration must be placed on antiepileptic drugs to increase their accessibility to common people. Drug Price Control Order (DPCO) and the National Pharmaceutical Pricing Authority (NPPA) are effective tools for regulation of drug prices. ${ }^{16-18}$ Thus, this study highlights that there exists a huge and variable price variation among the antiepileptic drugs manufactured by different companies and thus strong measures must be taken by the government and concerned agencies for uniformity in drug pricing. 
The limitation of the study is that sources of information were limited to CIMS but there are few other brands which are marketed in India but not published in the above mentioned source.

\section{CONCLUSION}

The present study findings showed a wide variation in the prices of different brands of same anti epileptic drugs currently available in Indian market. Increased adherence to the treatment can be ensured by decreasing the cost of therapy, by changes in the government policies and regulations and creating awareness among treating physicians for switching to cost effective therapy and thus help in rational prescribing.

To counteract such cost variation, the practice of generic prescribing should be encouraged. Prescribing of cheaper medications should be given greater emphasis among practitioners. Also spreading awareness that cheaper medicines are not inferior to costlier branded counterparts.

\section{ACKNOWLEDGMENTS}

The authors would like to thank the faculties and post graduate students of Department of Pharmacology of Bangalore Medical College and Research Institute, Bengaluru for their support in conducting the study.

\section{Funding: No funding sources}

Conflict of interest: None declared

Ethical approval: Not applicable

\section{REFERENCES}

1. Banerjee TK, Ray BK, Das SK, Hazra A, Ghosal MK, Chaudhuri A, et al. A longitudinal study of epilepsy in Kolkata, India. Epilepsia. 2010;51(12):2384-91.

2. Walker R, Whittlesea C. In: Clinical Pharmacy and Therapeutics.5th ed. London: Churchill Livingstone; 2012.

3. Paunikar AP, Bhave KA. Cost analysis of oral antidepressant drugs available in India. Natl J Physiol Pharm Pharmacol. 2015;5(5):1-5.

4. Kuruvilla A, George K, Rajaratnam A, John KR. Prescription patterns and cost analysis of drugs in a base hospital in south India. Natl Med J India. 1994;7(4):167-68.

5. Ravi Shankar P, Subish P, Bhandari RB, Mishra P, Saha AC. Ambiguous pricing of topical dermatological products. A survey of brands from two South Asian countries. Journal of Pakistan Assoctn of Dermatologists. 2006;16:134-40.
6. McNamara JO. Pharmacotherapy of the epilepsies. In: Brunton LB, Chabner BA, Knollman BC, eds. Goodman and Gilman's The Pharmacological Basis of Therapeutics. $12^{\text {th }}$ Ed. New York, McGraw- Hill; 2011:583-606.

7. Current Index of Medical Specialties, July- October 2016:199-206.

8. Jana S, Mondal P. Pharmacoeconomics: the need to sensitize undergraduate medical students. Indian J Pharmacol. 2005;37(5):277-8.

9. Shukla AK, Mehani R. Cost analysis of antiepileptic drugs available in India. Int $\mathrm{J}$ Basic Clin Pharmacol. 2016 Aug; 5(4):1636-40.

10. Phatak AM, Hotwani JH, Deshmukh KR, Panchal SS, Naik MS. Cost analysis of long established and newer oral antiepileptic drugs available in the indian market., Int J Med Res Health Sci. 2015;4(4):744-8.

11. Das SC, Mandal M, Mandal SC. A critical study on availability and price variation between different brands: Impact on access to medicines. Indian J Pharm Sci. 2007;69(1):160-63.

12. Shrank WH, Hoang T, Ettner SL, Glassman PA, Nair $\mathrm{K}$, DeLapp D, et al. The implications of choice: Prescribing generic or preferred pharmaceuticals improves medication adherence for chronic conditions. Arch Intern Med. 2006;166(3):332-7.

13. Das SC, Mandal M, Mandal SC. A critical study on availability and price variation between different brands: Impact on access to medicines. Indian $\mathbf{J}$ Pharm Sci. 2007;69(1):160-3.

14. World Health Organisation. Essential drugs and medicines: Drug finance. Available at: http://www.whoindia.org/EN/Section2/Section/Sectio n160_959.html.

15. Reichert S, Simon T, Halm EA. Physicians' Attitudes about Prescribing and Knowledge of the Costs of Common Medications. Arch Intern Med. 2000;160:2799-803.

16. Sakthivel S. Access to essential drugs and medicines. In: Lal PG, editor. National Commission on Macroeconomics and Health. New Delhi: Ministry of Health; 2005:185-210.

17. Kumar V, Gupta NV, Kumar KA. A comparison between old and latest systems in DPCO. International Journal of Pharmacy and Pharmaceutical Sciences. 2014;6(2):19-20.

18. Compendium of notified ceiling prices of scheduled drugs- NPPA; 2015. Available from: http://www.nppaindia.nic.in/ceiling price.

Cite this article as: Allisabanavar SA, Reddy NS. Cost variation analysis of various brands of antiepileptic drugs currently available in Indian pharmaceutical market. Int J Basic Clin Pharmacol 2017;6:1666-9. 